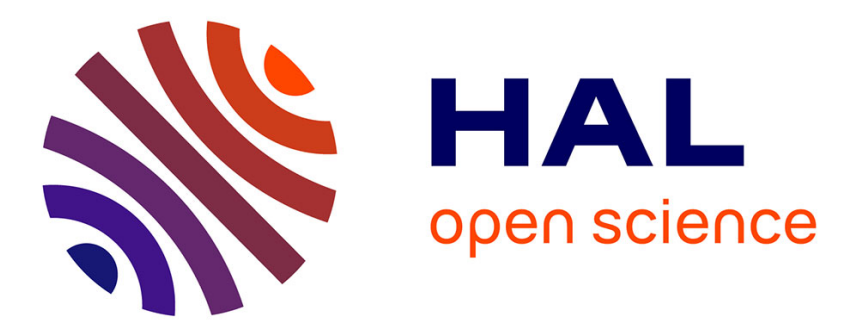

\title{
SAXS study of solutions of telechelic polymers in nonpolar solvents
}

\author{
P. Vanhoorne, C. Maus, G. van den Bossche, F. Fontaine, R. Sobry, R. \\ Jérôme, M. Stamm
}

\section{> To cite this version:}

P. Vanhoorne, C. Maus, G. van den Bossche, F. Fontaine, R. Sobry, et al.. SAXS study of solutions of telechelic polymers in nonpolar solvents. Journal de Physique IV Proceedings, 1993, 03 (C8), pp.C8-63-C8-66. 10.1051/jp4:1993813 . jpa-00252244

\section{HAL Id: jpa-00252244 https://hal.science/jpa-00252244}

Submitted on 1 Jan 1993

HAL is a multi-disciplinary open access archive for the deposit and dissemination of scientific research documents, whether they are published or not. The documents may come from teaching and research institutions in France or abroad, or from public or private research centers.
L'archive ouverte pluridisciplinaire HAL, est destinée au dépôt et à la diffusion de documents scientifiques de niveau recherche, publiés ou non, émanant des établissements d'enseignement et de recherche français ou étrangers, des laboratoires publics ou privés. 


\title{
SAXS study of solutions of telechelic polymers in nonpolar solvents
}

\author{
P. VANHOORNE ${ }^{*}$, C. MAUS, G. VAN DEN BOSSCHE ${ }^{* *}$, F. FONTAINE ${ }^{* * *}$, R. SOBRY ${ }^{* * *}$, \\ R. JERÔME and M. STAMM ${ }^{* * *}$
}

\begin{abstract}
Center for Education and Research on Macromolecules (CERM), Institute of Chemistry B6, University of Liège, Sart-Tilman, 4000 Liege, Belgium

"Fonds National de la Recherche Scientifique (FNRS), University of Liège, Sart-Tilman, 4000 Liege, Belgium

${ }^{* *}$ Unité de Cristallographie, Institute of Physics B5, University of Liège, Sart-Tilman, 4000 Liège, Belgium

*** Laboratoire de Physique Expérimentale, Institute of Physics B5, University of Liège, Sart-Tilman, 4000 Liège, Belgium

${ }_{* * * *}$ Max-Planck Institut für Polymerforschung, Ackermannweg 10, Postfach 3148, 55021 Mainz, Germany
\end{abstract}

\begin{abstract}
Influence of both polymer molecular weight and concentration, and solution preparation on the SAXS profile of $\omega$ - and $\alpha,(\omega)$-metal sulfonato and carboxylato polystyrenes in toluene has been investigated. For sulfonated polymers, position of the ionic peak obeys a general law which allows the phase morphology to be predicted. Ionic end-groups are phase-separated into small multiplets which act as physical crosslinks. Size of the multiplets does not depend on polymer molecular weight and concentration. Multiplets are homogeneously distributed throughout the polymer matrix, and organized in a liquid-like manner. Difunctional samples obey the same general behavior but only above a critical concentration which depends on the chain molecular weight. Although the position of the ionic peak is independent of the sample preparation, shape and intensity are clearly related to the large-scale heterogeneity of solutions.
\end{abstract}

\section{Introduction}

For more than 20 years, phase morphology of ionomers (hydrophobic chains containing less than $15 \mathrm{~mol} \mathrm{\%}$ of ionic groups) has been intensively investigated. The original properties of ionomers are usually accounted for by a microphase separation of the ionic groups from the polymer matrix. The ionic microdomains (also called "multiplets") act as thermoreversible crosslinks which greatly improve the mechanical properties. The SAXS profile exhibits a well-defined peak (the ionic peak), corresponding to Bragg distances of a few nanometers and attributed to intermultiplet interferences. Furthermore, the SAXS profile is also characterized by an important intensity upturn at very small scattering angles.

Although several models have been proposed for composition, shape and space distribution of the ionic microdomains, the actual phase morphology of ionomers still remains a pending question. It is the reason why a new class of ionomers, i.e. Halato-Telechelic Polymers (HTP's), has been synthesized on purpose (1). HTP's are linear chains bearing ionic groups selectively at both ends. The well-defined molecular architecture of these model compounds allows the influence of several parameters to be investigated in a straightforward way.

Recently, evidence has been reported for a long-range organization in some HTP's (2). For instance, Duplessix and Jalal (3) have investigated by SAXS solutions of $\omega$-baryum carboxylato polystyrene in toluene at $25^{\circ} \mathrm{C}$, and reported a hexagonal-type of supramolecular structure. According to these authors, semi-telechelic polymers (HSTP's), which are unable to form a three-dimensional network, are better models for ionomers than the parent HTP's. In order to know whether that behavior is general, solutions of $\omega$ - and $\alpha, \omega$-metal sulfonato polystyrenes in toluene have been analyzed by SAXS. 


\section{Experimental}

Telechelic carboxylato and sulfonato polystyrenes were synthesized by living anionic polymerization using mono- or difunctional initiators. Carboxylic acid and sulfonic acid end-groups were quantitatively neutralized with stoechiometric amounts of metal alkoxides and metal acetates, respectively, as reported elsewhere (4).

SAXS experiments were carried out at MPIP and LURE by using quartz tubes and special cells equipped with Kapton windows, respectively.

\section{Results and discussion.}

A series of $\omega$-baryum sulfonato polystyrenes $\left(\bar{M}_{n}=2800,6400,7700,13200\right.$ and 18400$)$, $\alpha$, $\omega$-baryum sulfonato polystyrene $\left(\overrightarrow{\mathrm{M}}_{\mathrm{n}}=7000,13900\right.$, and 23500$)$ and $\alpha, \omega$-baryum carboxylato polystyrene $\left(\overrightarrow{\mathrm{M}}_{\mathrm{n}}=\right.$ $5500,8000,10500$ and 17000) have been synthesized. Bulk polymers and solutions in toluene have been analyzed by SAXS.

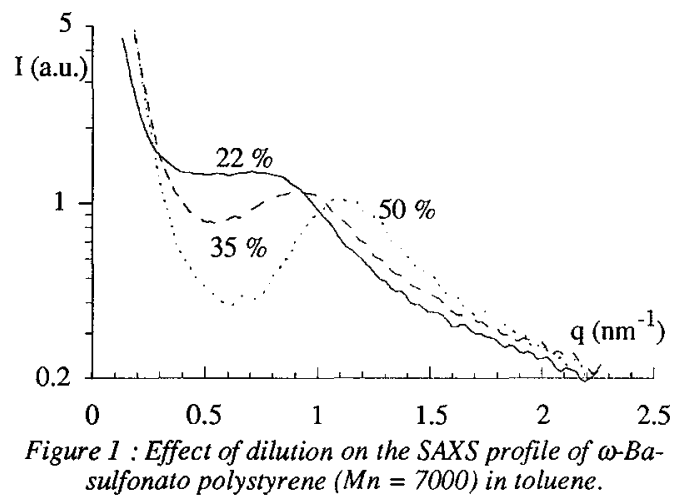

The typical effect of dilution on the SAXS profile is shown in Figure 1. As dilution is increased, the scattering maximum is continuously shifted towards lower angles, in agreement with a continuous increase in the intermultiplet distance. At lower concentrations, the ionic peak is poorly defined because of an increasing overlap with the small-angle intensity upturn.

Compared to HSTP's, HTP's are characterized by a critical concentration, $C_{p}$, below which the position of the ionic peak is independent of dilution. This unexpected behavior will be discussed later on.

Except for HTP's in the low concentration range, the dependence of $\mathrm{d}_{\mathrm{B} \text { ragg }}$ on polymer concentration, molecular weight and functionality of metal sulfonato end-groups obeys the following power law :

$$
\mathbf{d}=\mathrm{K}\left(\frac{\mathrm{M}_{\mathrm{n}}}{\mathrm{f} . \mathrm{C}}\right)^{1 / 3}
$$

where $\mathrm{f}$ is the end-functionality (either 1 or 2 ) of polystyrene chains, $\mathrm{C}$ is the chain concentration (vol \%) in toluene and $\overline{\mathrm{M}}_{n}$ is the number average molecular weight of polystyrene.

Figure 2 illustrates the validity of this general behavior for 65 experimental data covering the whole molecular weight range investigated. Obviously, metal sulfonato HSTP's are pertinent models for the space organization of the corresponding HTP's in toluene, except for the dilute solution regime, as previously emphasized.

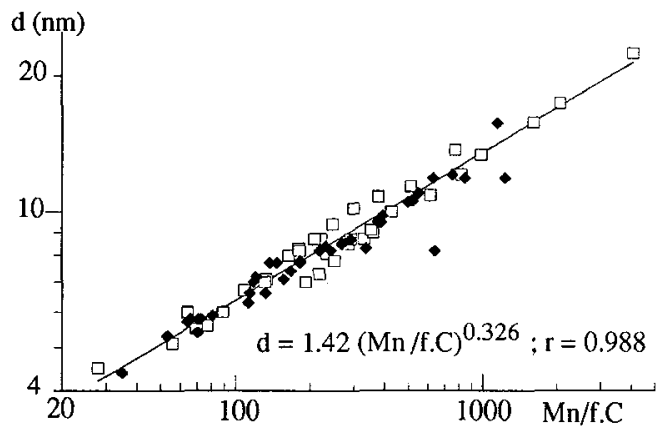

Figure 2 : Average intermultiplet distance versus dilution for Ba-sulfonato HTP's ( $)$ and HSTP's () in toluene.
The $1 / 3$ exponent in the general dilution law indicates an isotropic phase morphology (three-dimensional swelling). Two- or onedimensional swelling should give rise to a characteristic exponent of $1 / 2$ and 1 , respectively, as it would be expected for rod-like and lamellar morphologies, respectively (3). Moreover, it comes out from the $1 / 3$ exponent that the average number of chains per multiplet is independent of both the polymer concentration and molecular weight. Indeed, a decrease in the size of multiplets upon dilution should result in an exponent smaller than $1 / 3$ (5). The experimental results for metalsulfonato HTP's and HSTP's are thus in complete agreement with a liquid-like arrangement of stable multiplets, as it has been previously proposed for randomly sulfonated polystyrene ${ }^{(6)}$. 
No general behavior can be drawn for metal-carboxylato HTP's at a constant molecular weight. $\mathrm{d}_{\mathrm{Bragg}}$ depends on concentration at a power which ranges from 0.28 to 0.46 in an unpredictible way. Clearly, the space morphology of metal-carboxylato HTP's is different from that of the sulfonated counterparts, but no definite picture can be proposed at this stage. Further investigations on metalcarboxylato HSTP's and HTP's are currently in progress.

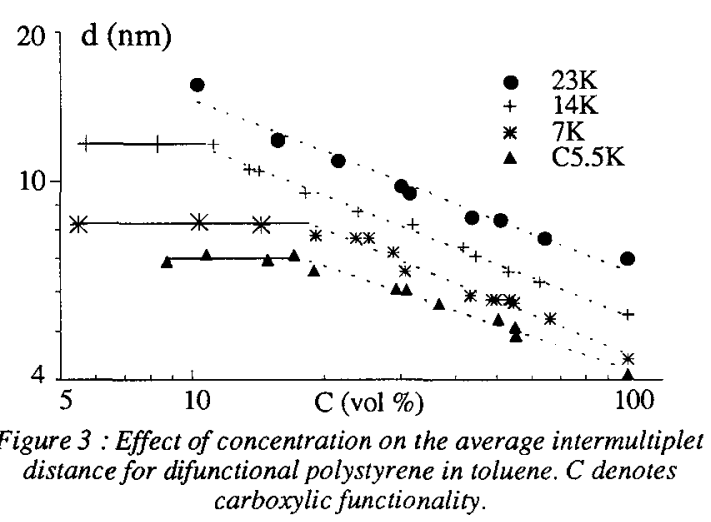

Nevertheless, metal-carboxylato as well as -sulfonato HTP's display the same characteristic behavior in the dilute regime. As shown in Figure 3 , the mean distance between multiplets remains constant below a critical concentration, $\mathrm{C}_{\mathrm{p}}$, which depends on the molecular weight of the prepolymer. This "plateau" extends up to higher concentrations as the chain lenght decreases. Its observation can thus be a problem for high enough molecular weights. This could be accounted for by a linear decrease of the multiplet size upon dilution, which would result in a characteristic exponent close to 0 and consequently in a constant intermultiplet distance. This explanation assumes that when the chains are fully extended, multiplets are unable to withstand the mechanical stress associated to an upper swelling ratio. An alternate explanation might be that beyond a critical swelling dictated by the full extension of the chains, microphase separation of excess toluene occurs, keeping constant the characteristic features of the gel. However, since homogeneous solutions are formed at high dilution, the former explanation seems to be more realistic.

Whatever the explanation, $C_{p}$ should correspond to the full extension of the chains interconnecting multiplets and is expected to decrease as the chain lenght increases, in agreement with the experimental data. When monofunctional polymers are concerned, multiplets are not interconnected and should not be perturbed by dilution, which fits with the observations.

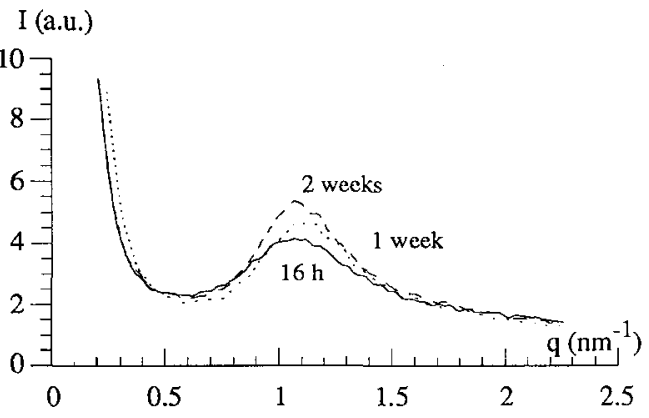

Figure 4 : Influence of sample equilibration time on the SAXS profile of $\alpha, \omega-B a$-sulfonato polystyrene $(M n=7000$. 50 weight \% in toluene).

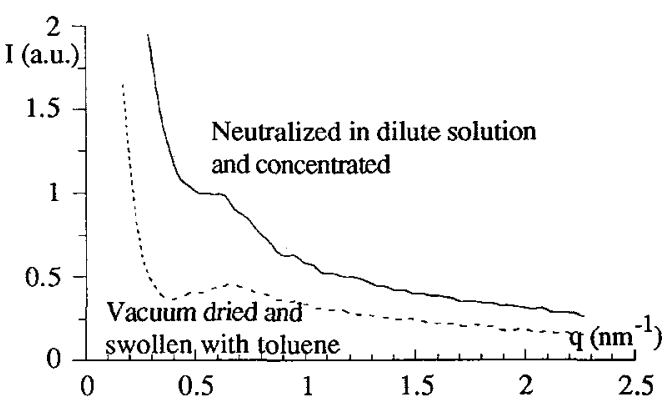

Figure 5 : Influence of dissolution method on the SAXS profile of $\alpha, \omega-B a$-sulfonato polystyrene $(\mathrm{Mn}=23500,35$ weight $\%$ in toluene).

As it can be seen from Figures 4 and 5 , neither the sample dissolution time nor the preparation mode have an effect on the position of the ionic peak. Peak intensity, however, is increased for solutions prepared several weeks before measurements (Fig.4). Moreover, samples prepared by dissolution of previously annealed and vacuum dried $\mathrm{H}(\mathrm{S}) \mathrm{TP}$ 's display the small angle intensity upturn at much smaller q values than samples directly prepared in solution (Fig.5). These effects are thought to be related to large-scale heterogeneities in the distribution of multiplets. The homogeneity of the sample would be increased upon annealing and increasing dissolution times. As a result, the small-angle upturn should be shifted towards lower q values and/or the intensity of the ionic peak should be increased. Additional experiments are under current investigation in order to elucidate this point. 


\section{Conclusions}

A SAXS study of solutions of $\omega$-and $\alpha, \omega$-baryum sulfonato polystyrenes in toluene has concluded to the association of the ion pairs into stable multiplets distributed isotropically throughout the polymer matrix. There is no structural discontinuity neither between mono and difunctional samples, nor between bulk state and solution. A general law has been derived for the average intermultiplet distance as a function of the molecular parameters of the chains. This equation is no longer valid to difunctional $\alpha, \omega$-polymers below a critical concentration at which the chain extension is maximum; upon further dilution, partial multiplet dissociation would be responsible for the observed invariance of the intermultiplet distance. $\alpha, \omega$-baryum carboxylato polystyrenes display a phase morphology which is clearly distinct from that of the sulfonated counterparts. However, no definite model can be proposed for these systems at this stage. More detailed investigations are currently in progress.

For all the samples, the position of the ionic peak has been shown to be independent of the sample preparation, but the overall shape of the SAXS profile can be related to the large-scale heterogeneity of solutions.

\section{Acknowledgements}

The authors are very much indebted to the "Service de la Programmation de la Politique Scientifique" (SPPS, Brussels) and to the "Fonds National de la Recherche Scientifique" (FNRS) for one of them (P.V.).

\section{References}

1) Williams, C.E.; Colliex, C.; Horrion, J.; Jérôme, R., in "Multiphase Polymers : Blends and Ionomers", Utracki, L.A.; Weiss, R.A., Eds, ACS Symposium Series 995, ACS, Washington D.C., 1989, Chapter 18

2) Fontaine, F.; Ledent, J.; Sobry, R.; François, E.; Jérôme, R.; Teyssié, Ph., Macromolecules, 1993, 26, 1480

3) Jalal, N.; Duplessix, R.; J. Phys. France, 1988, 49, 1775

4) Broze, G.; Jérôme, R.; Teyssié, Ph., Macromolecules, 1982, 15,920

5) Eisenberg, A.; Hird, B.; Moore, R.B., Macromolecules, 1990, 23, 310

6) Wu, D.Q.; Chu, B.; Lundberg, R.D.; MacKnight, W.J.; Macromolecules, 1993, 26, 1000 